Article

\title{
Nutrient Resources Recovery By A Creative Co- Composting Method of Municipal Solid Wastes and Wastewater Treatment Plant Sludge
}

\author{
Saeed Nemati ${ }^{* 1}$, Bijan Samali ${ }^{1}$, Farzaneh Tahmoorin ${ }^{2}$, Nader Mokhtarani ${ }^{3}$, Farshad Sanati 4 \\ ${ }^{1}$ Centre for Infrastructure Engineering, Western Sydney University, Australia; Nematiuts@gmail.com , \\ B.Samali@uws.edu.au \\ ${ }^{2}$ School of Engineering and Technology, Central Queensland University, Australia; F.Tahmoorian@cqu.edu.au \\ ${ }^{3}$ Civil and Environmental Engineering Faculty, Tarbiat Modares University, Iran; mokhtarani@modares.ac.ir, \\ ${ }^{4}$ Consulting Department, Wala Energy Engineering Co., Iran; Sanati.farshad@yahoo.com \\ *Corresponding Author: Nematiuts@gmail.com
}

\begin{abstract}
The purpose of this study is nutrient resources recovery by achieving the optimal chemical oxygen demand $(\mathrm{COD})$ and carbon to nitrogen ratio $(\mathrm{C} / \mathrm{N})$ in co-composting wastewater treatment plant sludge with Municipal Solid Wastes (MSW). In this effort, the co-composting has been conducted in form of a case study in the northern region of Iran. In this research, 192 tests were carried out on four series of samples examined in terms of waste to sludge ratio, different aeration period, the percent of porous materials and the moisture content. This study was carried out at a temperature of $50^{\circ} \mathrm{C}$ for a 15 day period by application of the in-vessel system and shows that the best ratio for waste to sludge is $2: 1$, while the 8 hour period is the best aeration period. The porous material which can be added to the composting process is limited to $15 \%$ in weight. In other words, any more or less amount of this material will adversely impact the process. Moreover, this research suggests that the sludge dewatering is not required in such processes. In Addition, the efficiency of both COD and C/N reductions equals to about $40 \%$.
\end{abstract}

Keywords: Nutrient Resources Recovery , Chemical Oxygen Demand (COD), Carbon to Nitrogen Ratio $(\mathrm{C} / \mathrm{N})$, Co-Composting, Wastewater Sludge, Municipal Solid Wastes (MSW)

\section{Introduction}

The rapid growth of industrial and technological advancements, coupled with rapid population growth have led to two major challenges in relation to generated urban solid waste and wastewater. Although various methods have been proposed for disposal of these materials, each of the available methods has certain disadvantages and demand development of more advanced methods to tackle the problems. Urban wastewater treatment has long been performed in a variety of ways, with almost all facing the challenge of filtration the resulting sludge. This sludge, while highly polluted, has abundant of water, which causes major problems in its management, and it is very difficult for any conventional solution to deal with it, such as dewatering, landfilling, spreading, etc. Meanwhile, co-composting is known as a potential solution to this problem [1]. On the other hand, chemical oxygen demand (COD) and Carbon to Nitrogen ratio $(\mathrm{C} / \mathrm{N})$ are two important parameters in composting as they affect other parameters such as microorganism's activities. By determining the optimum ratio of municipal solid waste (MSW) and 
wastewater sludge, this paper aims to present a sustainable co-compost solution. Therefore, the reduction of $\mathrm{COD}$ or $\mathrm{C} / \mathrm{N}$ to an optimal level usually leads to other optimal parameters. In addition, they are chosen as maturity indicators. In this study using simultaneous optimization of $\mathrm{COD}$ and $\mathrm{C} / \mathrm{N}$ for wastewater sludge and municipal waste co-composting, the optimal amounts of four co-composting design parameters including aeration period, the percent of porous material, the moisture content and waste to sludge ratio are determined.

\section{Research background}

Composting has become precious in the stabilization of MSW due to its environmental adaptability. Every year, extensive studies have been undertaken on solid waste management systems, especially compost systems. However, published articles focusing on co-composting of MSW and wastewater sludge are very limited. For example, Shuval et al. during 1981 to 1989, carried out several economization tests on various co-composting materials with different proportions. They stated that co-composting of wastewater sludge with any organic substance waste is possible, but economic issues play an important role in choosing the primary ratios [2]. Onwosi et al. proposed different types of composting methods reportedly applied in waste management [3]. Also, the critical factors such as temperature, $\mathrm{pH}, \mathrm{C} / \mathrm{N}$, moisture content, the particle size that have been considered relevant in the monitoring of the composting were clarified. Appropriate procedures to enhance and optimize process effectiveness were also addressed. Still, during composting, some difficulties such as leachate generation, gas emission and lack of consistency in assessing maturity indices were imminent. In their study, these challenges were, and some strategies for improving them were presented. Ultimately, they highlighted some novel technologies that could improve composting. Cofie et al. presented the potentials and performance of mixed treatment of fecal sludge (FS) and MSW by co-composting [4]. The aims were to study the relevant MSW type, MSW/FS mixing rate and the outcome of turning rate on compost quality. Specimens were taken at each turning and examined for total solids, electrical conductivity, total volatile solids, total organic carbon, $\mathrm{pH}$, ammonium and nitrate nitrogen and total Kjeldahl nitrogen. Results showed there was no meaningful effect of various turning repetitions on the temperature changes and the quality of compost. Other researchers studied the cocomposting performance of sewage sludge (SS) and organic fraction of municipal solid waste (OFMSW) at various proportions [5]. Results revealed that higher SS proportion could quickly initialize the process; while raising OFMSW prolonging the thermophilic period and expanding the humification degree. But, extreme OFMSW wanted a longer co-composting period to ensure great compost maturity and quality. Other study focused on the impact of different bulking waste such as wood shaving, combined with an OFMSW composting within evaluating their influence on microbial enzymatic actions and kind of completed compost [6]. The outcomes revealed that OFMSW mixed with wood shaving and the microbial consortium was a suitable tool to help the enzymatic activity and the shortened composting time. Cai et al. carried out four test series on co-compost of wastewater sludge and rice husk, and they showed that much of the semi-volatile organic compounds excluded from the compost after 56 days [7]. Using anaerobic pilot reactor, some researchers evaluated a composting mixture of municipal solid waste, wastewater treatment sludge, wood chips and a series of enzymes [8]. Referring to their study, the type of the combining material in addition to the type of the composting material, and the composition ratios of these materials have also a substantial influence on the quality of the final product. Brinton examined the history of compost appreciation and particularly looks at the emerging awareness of the need to distinguish composts from other re-cycled wastes and common fertilizers [9]. In other research, lab tests using sewage sludge as an underlying substrate for composting are presented [10]. Values of characteristic parameters for the composting process, fat content and lipolytic enzymatic action were observed in aerated static lab-size composters. Results showed co-composting with sewage sludge can be counted as a viable option to treat solid wastes in high proportions up to $40 \%$ although a maximum ratio of $20 \%$ may be advised to avoid 
long composting periods. The influences of various municipal organic waste (MOW) on biological matter stabilization and compost quality were considered by Tognetti et al. [11]. Results showed shredded treatments presented faster organic matter stabilization than non-shredded treatments. Wood shavings addition significantly improved the quality of compost but decreased total nitrogen and available nutrient concentrations. Zhanga et al. [12] investigated the main physicochemical characteristics, i.e., $\mathrm{pH}$ and electrical conductivity (EC), in co-composting pine sawdust with fresh solid swine manure. The results intimated that $\mathrm{N}$ and $\mathrm{P}$ decay primarily happened in the mesophilic phase, while organic carbon crumbled in the thermophilic phase and $30 \%$ swine manure with initial $\mathrm{C} / \mathrm{N}$ ratio of about 40 was more desirable for composting organic substrates. In a similar work, Millán [13] developed a field trial of co-composting municipal solid organic waste with wastewater treatment plants (WWTP) sludge in a municipality of Boyacá, finding the optimum proportion of these materials, characterizing the two raw materials and the most suitable mixture. Yang et al. [14] studied co-composting of yard trimmings (YT) and food waste (FW). The goal was to investigate the proper yard trimmings/food waste mixing ratio. Results showed that 1:1 mixing ratio was the best ratio, where the $\mathrm{C} / \mathrm{N}$ ratio was 14.15. Bian et al. [15] studied the influences of matured sewage sludge (MSS) amendment on N2O emissions during aerobic co-composting of MSW. The results confirmed that MSW composting with MSS amendments enhanced $\mathrm{N} 2 \mathrm{O}$ emissions during the beginning stage.

\section{Methodology}

This study has been done using "Co-Composting Optimization Laboratory Reactor" which is registered under the IP number of IR-388030506 by Saeed Nemati (Figure 1).

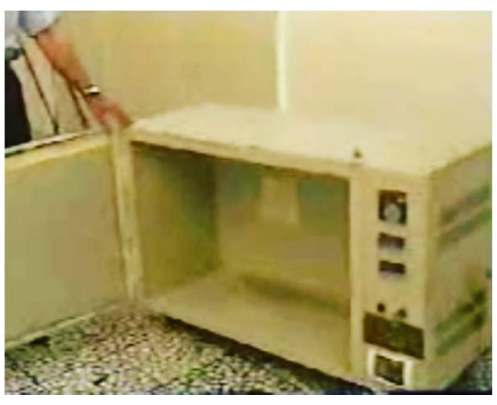

Fig 1. Co-Composting Optimization Laboratory Reactor

This system consists of a closed chamber, with the length of $1,100 \mathrm{~mm}$ and a width of $700 \mathrm{~mm}$ and a height of $900 \mathrm{~mm}$. Four cylindrical vessels were placed in this chamber. Auto elements and digital sensors continuously controlled ambient temperature. Four side walls of the frame were made from fiberglass sandwich panels with double galvanized facings in order to reduce heat exchange. Each cell had a cylindrical shape with a diameter of $550 \mathrm{~mm}$ and a height of $600 \mathrm{~mm}$. In this system, the ambient temperature is controlled by a digital heating system initially. As the temperature increases, the sensors will act and attempt to cut off the flow of electricity to the elements. However, it takes a long time to drop the temperature due to very good insulation system. Depending on the desired accuracy, the amount of heat loss can be defined from zero to ten Celsius degrees. The pilot is also equipped with a central switch, fuse, and function indicator. Furthermore, two external fans were installed in this reactor as air blowers and a heat-gas exhaust which enabled the operator for a range of aeration types, so that the fan can be turned on and a thermal sensor or its functional interval can be set using a digital timer for both. In the absence of any specific program, manual control of these fans is possible. In this study, an origin separation phase was conducted on MSW. In the next stage, going to a mill this material will have the approximate 
dimensions of $4 \mathrm{~cm}$, which is suitable for compost and has a great effect on the fast reduction of organic carbon rate. Tiny wood chips with the approximate area of 1,200 mm2 were used to control the system's $\mathrm{C} / \mathrm{N}$. In addition, to produce the needed porosity, flexible PVC parts with an approximate length of $20 \mathrm{~mm}$ was used (Figure 2). The $\mathrm{pH}$ of used waste and wastewater sludge were 6.1 and 7.6 respectively.

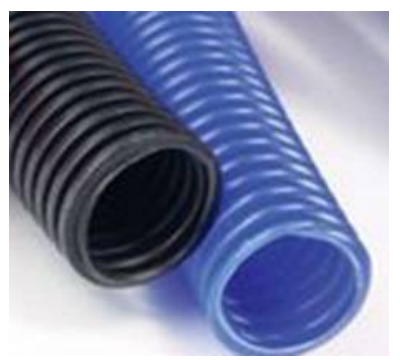

Fig 2. Porosity providing additives

\section{Test series}

In this study, four series of tests were designed and conducted as follows:

\subsection{Series 1: Determination of the optimum portions of waste and sludge}

- Constant parameters: temperature, number of aeration and initial C/N

- Variable parameters: mixture portions

- Sampling period: every 3 days

- Test duration: 15 days

- Controlling parameters: COD and C/N variation (based on EPA and ASTM methods) [16-17].

In this series, the temperature was kept at $50^{\circ} \mathrm{C}$ for two weeks. All samples were aerated once every 8 hours for twenty minutes, by mixing the content of the tank. Moreover, $\mathrm{C} / \mathrm{N}$ ratio for all samples was kept constant at 25, by changing the mixing ratio and the number of wood chips. Regarding the similar specific gravity of the existing sludge to the applied waste chip, both volumes and weight ratios can be used. However, the criterion is calculated based on weight ratios. This fact will facilitate and expedite the operations at industrial scale, due to the possibility of applying large scales. In this series of tests, a high level of dewatering of the sludge was prevented in order to provide a suitable condition for a rapid composting process. Table 1 shows waste to sludge ratio in tanks.

Table 1. Waste to sludge ratio in tanks

\begin{tabular}{|c|c|}
\hline Tank No. & Waste to sludge ratio \\
\hline A1 & $1: 1$ \\
\hline A2 & $2: 1$ \\
\hline A3 & $3: 1$ \\
\hline A4 & $4: 1$ \\
\hline
\end{tabular}

4.2. Series 2: Constant parameters: Temperature, mixture portions 


\section{4}

- Constant parameters: mixture portions, initial $\mathrm{C} / \mathrm{N}$ and initial COD

- Variable parameters: aeration frequency and duration (times of aeration)

- Sampling period: every 3 days

- Test duration: 15 days

- Controlling parameters: COD and $\mathrm{C} / \mathrm{N}$ variation

In this series, the optimum mixture portions (blending ratio) had been considered for all four tanks while they were aerated for two weeks based on Table 2.

Table 2. Aeration Condition

\begin{tabular}{|c|c|c|}
\hline Tank No. & Aeration frequency & Aeration Duration \\
\hline B1 & \multicolumn{2}{|c|}{ continuous aeration } \\
\hline B2 & every 8 hours & 15 minutes \\
\hline B3 & every 16 hours & 15 minutes \\
\hline B4 & every 24 hours & 15 minutes \\
\hline
\end{tabular}

\subsection{Series 3: Determination of optimum amount of additives for increasing porosity}

- Constant parameters: temperature, mixture portions, times of aeration, initial C/N and initial COD

- Variable parameters: amount of additives for increasing porosity

- Sampling period: every 3 days

- Test duration: 15 days

- Controlling parameters: COD and $\mathrm{C} / \mathrm{N}$ variation

In this series, different amount of additives were added to the samples in order to determine the optimum amount for the best level of porosity. The evaluated ratios are shown in Table 3.

Table 3. Amount of additives in each tank

\begin{tabular}{|c|c|c|c|c|}
\hline Tank No. & C1 & C2 & C3 & C4 \\
\hline Additives amount (by volume) & $5 \%$ & $10 \%$ & $15 \%$ & $20 \%$ \\
\hline
\end{tabular}

\subsection{Series 4: Optimum moisture determination}

- Constant parameters: temperature, mixture portions, times of aeration, amount of additives for increasing porosity, initial $\mathrm{C} / \mathrm{N}$ and initial COD

- Variable parameters: moisture content of sludge cake

- Sampling period: every 3 days

- Test duration: 15 days

- Controlling parameters: COD, $\mathrm{C} / \mathrm{N}$ and weight variation 
172

173

174

175

176

177

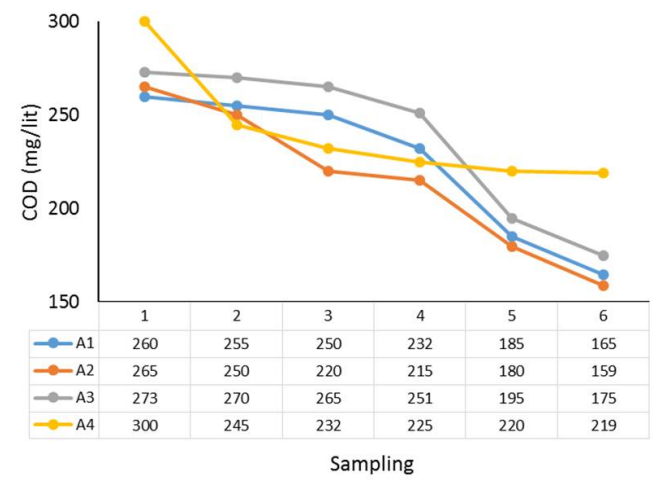

$\rightarrow \mathrm{A} 1 \rightarrow \mathrm{A} 2 \rightarrow \mathrm{A} 3 \rightarrow \mathrm{A} 4$

\section{Results and discussion}

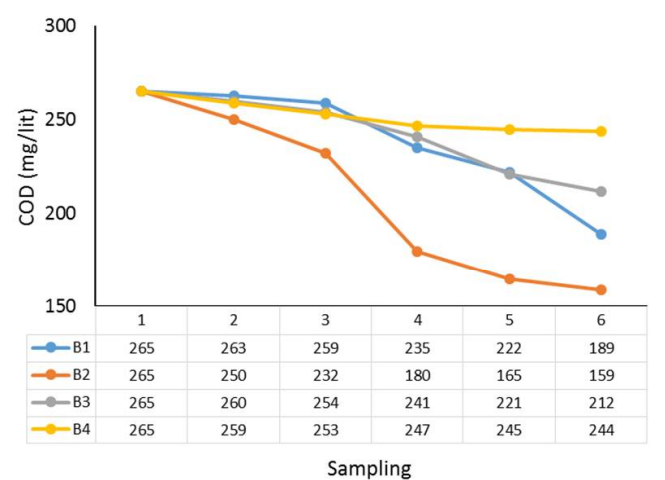

$\rightarrow B 1 \rightarrow B 2 \rightarrow B 3 \rightarrow B 4$
Table 4. Moisture content in each tank

\begin{tabular}{|c|c|c|c|c|}
\hline Tank No. & D1 & D2 & D3 & D4 \\
\hline Moisture content & $30 \%$ & $40 \%$ & $60 \%$ & not dewatered \\
\hline
\end{tabular}

Figures 3 to 6 illustrate the results of COD control in the first series of tests in a 15- day period.

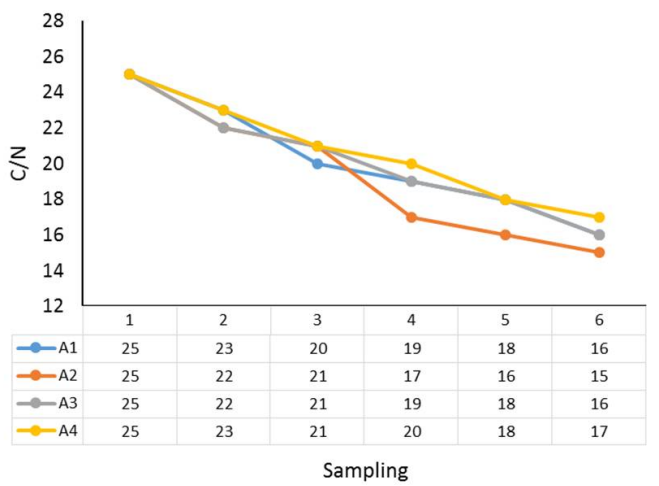

$\rightarrow \mathrm{A} 1 \rightarrow \mathrm{A} 2 \rightarrow-\mathrm{A} 3 \rightarrow \mathrm{A} 4$

Fig 3. COD (left) and $C / N$ (right) variation in different tanks after 15 days in the first series of tests

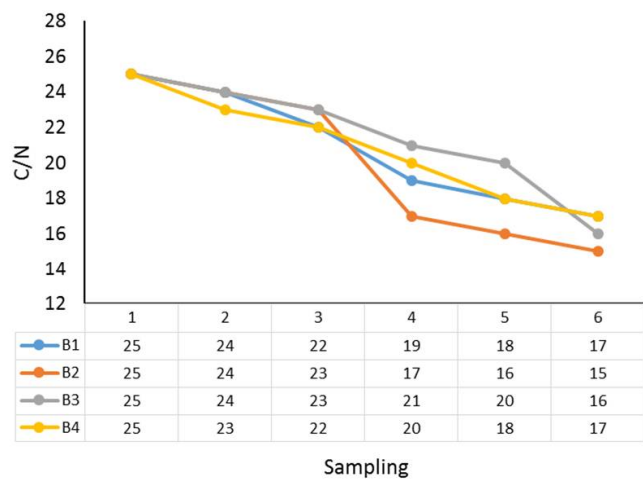

$\rightarrow$ B1 $\rightarrow$ B2 $\rightarrow$ B3 $\rightarrow$ B4

Fig 4. COD (left) and $\mathrm{C} / \mathrm{N}$ (right) variation in different tanks after 15 days in the second series of tests 

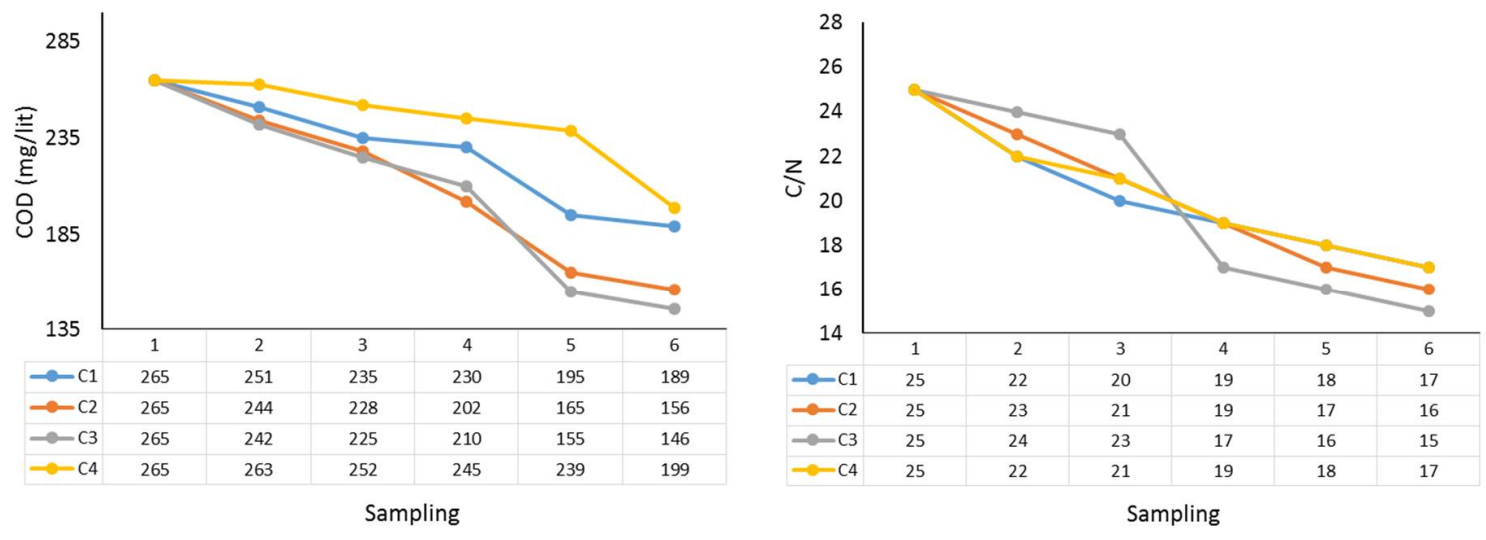

Fig 5. COD (left) and $\mathrm{C} / \mathrm{N}$ (right) variation in different tanks after 15 days in the third series of tests

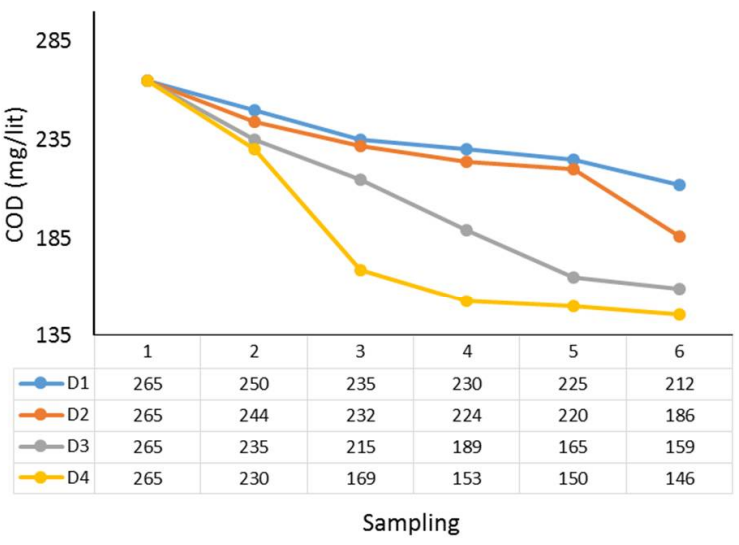

$\rightarrow \mathrm{D} 1 \rightarrow \mathrm{D} 2 \rightarrow \mathrm{D} 3 \rightarrow \mathrm{D} 4$

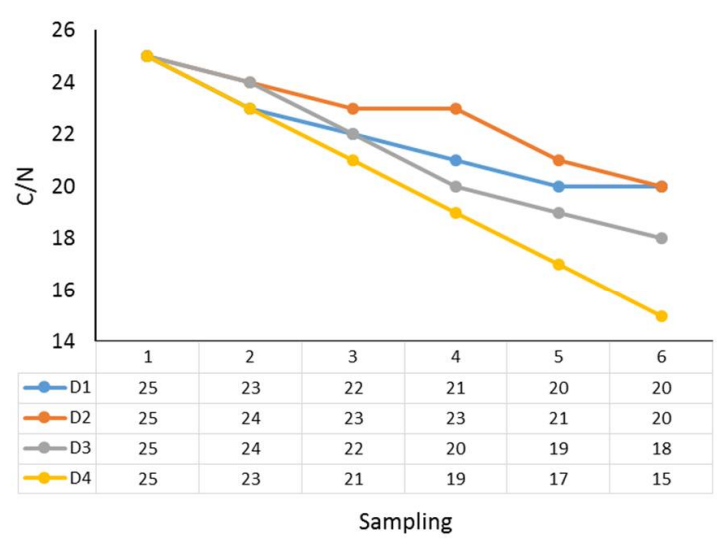

$\because \mathrm{D} 1 \multimap \mathrm{D} 2 \multimap \mathrm{D} 3 \multimap \mathrm{D} 4$

Fig 6. COD (left) and C/N (right) variation in different tanks after 15 days in the fourth series of tests

The results of COD investigation in the first series of tests revealed that in tank 2 with waste to sludge ratio of $2: 1$, COD reduced by $40 \%$ and hence this sample experienced the most successful composting process. A $100 \%$ increase in the ratio of waste to sludge (tank 2 / tank 1$)$ results in an $8 \%$ increase in system efficiency, one of the reasons being the increase in the microbial substrate. However, re-increasing this ratio almost linearly reduces the efficiency of the system (Figure 7). This negative effect can be attributed to the excessive amount of toxic gases produced by microorganisms, as well as the lack of nitrogen and the imbalance between organic carbon and nitrogen. Furthermore, the process was not stopped inside the tank 2 in any period that is the evidence of system stability. Therefore, it can be concluded that the optimum waste to sludge ratio is 2:1. This ratio dictates an initial COD of 265 for the second series of tests. Examining the $\mathrm{C} / \mathrm{N}$ changes also shows the same behaviour in the tanks (Figures 3 and 8). In the second test series for continuous aeration, the door of tank 1 was opened and air blew continually. Also, due to the impossibility of continuous humidity control in continuous aeration, the primary moisture was set as the criterion. Finally, the results of $\mathrm{COD}$ and $\mathrm{C} / \mathrm{N}$ were obtained as illustrated in Figure 4 . In this series of tests, it was also observed that $40 \%$ of both COD and $\mathrm{C} / \mathrm{N}$ reduction occurred in tank 2 (Figures 7 and 8 ). This indicates that an 8 -hour increase in aeration intervals resulted in a $20 \%$ reduction in system efficiency, which is due to the reduction of the available amount of oxygen for the microorganisms. In addition, although the 
aeration intervals increased linearly, efficiency reduction process is non-linearly affected. This efficiency reduction is exactly as much as the amount which occurs if continuous aeration is applied. In other words, if extended aeration is applied to the system, due to the rapid loss of moisture, biological processes are impaired but its maximum would be $32 \%$. Therefore, in this situation, the optimum aeration is the period of 8 hours. As illustrated in Figures 7 and 8, the highest composting for both COD and C/N removal rate in the third series of tests occurs in tank 3 during almost the first 12 days of system launch and after this period, it has remained relatively constant. In addition, it was also observed that the reductions of COD and $\mathrm{C} / \mathrm{N}$ are $45 \%$ and $40 \%$, respectively. During the first six days of the system launch, three other tanks had a slow decline. This continued for COD reduction in tank 4 for the entire 15 days. It can be seen that any percentage of additives to increase porosity other than the $15 \%$, causes the reduction of COD removal rate. Therefore, in real scale, applying this amount of porosity producing additives are recommended. As can be seen from this diagram, changing the amount of this material from $5 \%$ to $10 \%$ does not significantly change the $\mathrm{C} / \mathrm{N}$ ratio. Also, $20 \%$ of this material, due to its high porosity, causes early evaporation of the moisture, resulting in about $50 \%$ reduction in the efficiency of the system. The most important point is that, although the best $\mathrm{C} / \mathrm{N}$ ratio is achieved at $15 \%$ porosity, this amount is exactly the same as in the absence of such additives. The reason for this is that porosity of up to $15 \%$ does not alter significantly in oxygen uptake of microorganisms, but higher than $15 \%$ it can reduce the efficiency of the system by decreasing the local moisture content. In addition, it was also observed that the reductions of COD and C/N are $45 \%$ and $40 \%$, respectively. As can be seen, tank 4, which has un-dewatered sludge, has the best composting process with a $40 \%$ reduction in $\mathrm{C} / \mathrm{N}$ ratio. Dewatering up to $60 \%$ has reduced its efficiency by up to $30 \%$. In the same way, dewatering to 40 and 30 percent, without having a significant difference, caused another $30 \%$ reduction in the efficiency of the system. Hence, the needs of microorganisms involved in the composting process to high humidity can be determined. In the fourth series of tests, the optimum moisture content has been evaluated only by varying the moisture content of sludge cake as 30,40 and 60 percent in the first three tanks and non-dewatered cake in the fourth tank. It can be observed that the highest rate of compost COD loss, as well as $\mathrm{C} / \mathrm{N}$ changes, occur in tank 4 (Figures 7 and 8). After about 6 days, the COD reduction rate in this tank increased by $65 \%$. This reduction rate is the same for moisture contents of $30 \%$ and $40 \%$ and equals $10 \%$ over six days. Therefore, it can be concluded that the microorganisms involved in the cocomposting need high moisture content.

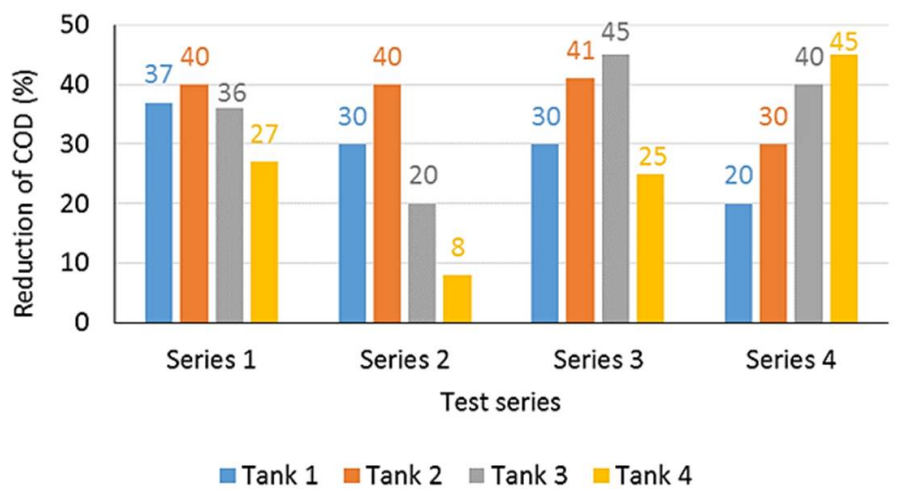

Fig 7. Comparison between COD variations in different test series 


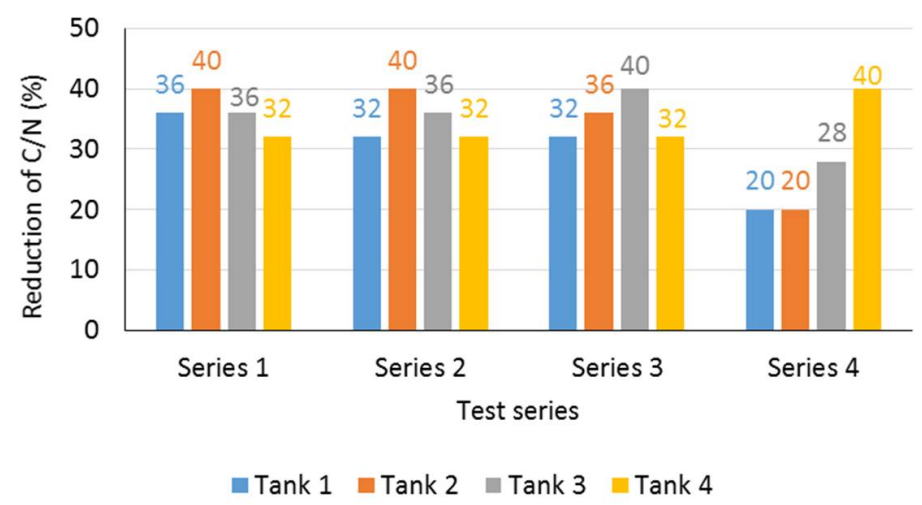

Fig. 8. Comparison between $\mathrm{C} / \mathrm{N}$ variations in different test series

According to the findings of this research, the following results can be obtained regarding in-vessel cocomposting of municipal wastes with wastewater treatment plant sludge:

- Co-composting of municipal wastes with wastewater treatment plant sludge must be done without any dewatering.

- At the temperature of $50{ }^{\circ} \mathrm{C}$ and a constant carbon to nitrogen ratio, if an 8- hour aeration period is applied, the maximum loss of COD occurs in the MSW to sludge ratio of 2 . In this situation, the maximum loss of both COD and $\mathrm{C} / \mathrm{N}$ are equal to $40 \%$.

- An 8-hour increase in aeration intervals causes a $20 \%$ system efficiency decrease

- At the temperature of 50 degrees $C$, the optimum amount of porosity producing additives is $15 \%$ of the mixture volume.

\section{References}

16. ASTM D5975-17, Standard Test Method For Determining The Stability Of Compost By Measuring Oxygen Consumption.

6. Awasthi, M. K., Pandey, A. K., Bundela, P. S., \& Khan, J. (2015). Co-composting of organic fraction of municipal solid waste mixed with different bulking waste: characterization of physicochemical parameters and microbial enzymatic dynamic. Bio resource technology, 182, 200-207.

15. Bian, R., Sun, Y., Li, W., Ma, Q., \& Chai, X. (2017). Co-composting of municipal solid waste mixed with matured sewage sludge: The relationship between $\mathrm{N} 2 \mathrm{O}$ emissions and denitrifying gene abundance. Chemosphere, 189, 581-589. DOI: 10.1016/j.chemosphere.2017.09.070

9. Brinton, W. F. (2000). Compost quality standards and guidelines. Final report by woods end research laboratories for the New York state association of recyclers.

7. Cai, Q. Y., Mo, C. H., Wu, Q. T., Zeng, Q. Y., \& Katsoyiannis, A. (2007). Quantitative determination of organic priority pollutants in the composts of sewage sludge with rice straw by gas chromatography coupled with mass spectrometry. Journal of Chromatography A, 1143(1-2), 207-214. DOI: 10.1016/j.chroma.2007.01.007

4. Cofie, O., Kone, D., Rothenberger, S., Moser, D., \& Zubruegg, C.(2009). Co-composting of faecal sludge and organic solid waste for agriculture: Process dynamics. Water research, 43(18), 4665-4675. DOI: 10.1016/j.watres.2009.07.021

10. Gea, T., Artola, A., \& Sánchez, A. (2004). Co-composting sewage sludge and fats. Optimal ratios and process evolution. Sustainable Organic Waste Management for Environmental Protection and Food Safety. Organic Waste Treatments: Safety Implications.

8. Grube, M., Lin, J. G., Lee, P. H., \& Kokorevicha, S. (2006). Evaluation of sewage sludge-based compost by FT-IR spectroscopy. Geoderma, 130(3-4), 324-333. doi:10.1016/j.geoderma.2005.02.005

2. IWMI\&SANDEC (2002). Co-composting of Faecal Sludge and Solid Waste, Preliminary Recommendations on Design and Operation of Co-composting Plants based on the Kumasi Pilot Investigation. 
1. Körner, I., Saborit-Sánchez, I., \& Aguilera-Corrales, Y. (2008). Proposal for the integration of decentralized composting of the organic fraction of municipal solid waste into the waste management system of Cuba. Waste Management, 28(1), 64-72. DOI: 10.1016/j.wasman.2006.12.009

13. Millán, G. L. C. (2017). Co-Composting of Solid Waste Organic Urban with Sludge. International Area Studies journal, 21(2), 23-36.

17. O'Dell, J. W. (1993). Method 410.4, Revision 2: The determination of chemical oxygen demand by semi-automated colorimetry. US Environmental Protection Agency Cincinnati, Ohio.

3. Onwosi, C. O., Igbokwe, V. C., Odimba, J. N., Eke, I. E., Nwankwoala, M. O., Iroh, I. N., \& Ezeogu, L. I. (2017). Composting technology in waste stabilization: on the methods, challenges and future prospects. Journal of environmental management, 190, 140-157. DOI: 10.1016/j.jenvman.2016.12.051

11. Tognetti, C., Mazzarino, M. J., \& Laos, F. (2007). Improving the quality of municipal organic waste compost. Bio resource Technology, 98(5), 1067-1076. DOI: 10.1016/j.biortech.2006.04.025

14. Yang, W., Jin, F., \& Chen, M. (2014). The effect of different mixing ratio on co-composting of yard trimmings and food waste. In Materials for Renewable Energy and Environment (ICMREE), 2013 International Conference on (Vol. 1, pp. 303-307). IEEE. DOI: 10.1109/ICMREE.2013.6893671

5. Zhang, D., Luo, W., Li, Y., Wang, G., \& Li, G. (2018). Performance of co-composting sewage sludge and organic fraction of municipal solid waste at different proportions. Bio resource Technology, 250, 853-859. DOI: 10.1016/j.biortech.2017.08.136

12. Zhanga, Y., \& He, Y. (2006). Co-composting solid swine manure with pine sawdust as organic substrate. Bio resource Technology, 97(16), 2024-2031. DOI: 10.1016/j.biortech.2005.10.004 